XXIII.

Aus der I. medicinischen Klinik der Universität Berlin.

\title{
Ueber einen neuen Befund beim Eiweissabbau des
} Diabetikers.

\author{
Von \\ Peter Bergell und Ferdinand Blumenthal.
}

Es ist bekannt, dass die Wirkung der tryptischen Enzyme, welche die Verkettungen von Aminosäuren hydrolytisch spalten, relativ streng asymmetrisch verläuft. Aus der Fermenthydrolyse resultiren die natürlich vorkommenden Aminosäuren als freie Yerbindungen, und war das Substrat aus inactiven Verbindungen synthetisch construirt, so blciben die asymmetrischen Complexe zurück, deren Bausteine die in der Natur nicht vorkommenden Substanzen sind, die Spiegelbilder der durch das verdauende Enzym abgespaltenen Säuren. Embden ${ }^{1}$ ) hat nun gefunden, dass bei einer gewissen Ueberschwemmung des Organismus mit per os dargereichter inactiver Aminosäure, dem Alanin, ein Theil der Säure im Harn als optisch activ anzutreffen ist. Und es wurde festgestellt, dass es sich hier um das L-Alanin, die in der Natur nicht vorkommende Hälfte des Racemkörpers, handeln muss. Es scheint also, dass dieser Stoffwechselprocess, den wir doch in erster Linie als einen Verbrennungsprocess zu betrachten gewohnt sind, in seinen quantitativen Verhältnissen eine configurative Selection zeigt.

Wir haben nun bei der Beschäftigung mit diesen Dingen einige Unterschiede beobachtet zwischen dem fortgeschritten diabetischen Organismus und dem in seiner Kohlehydratverarbeitung nicht oder. weniger gestörten.

Wir haben häufig beim Menschen 10-15 g inactives und zuweilen auch actives (bis $9 \mathrm{~g}$ ) Alanin verfüttert und darauf den Harn der Naphthalinsulfochloridreaction unterworfen. Hierbei zeigt sich zunächst, dass beim Gesunden eine grössere Menge des Derivates der Aminosäuren nicht erhältlich ist. Wir haben die Reaction stets in gewohnter Weise angestellt und gleichmässig mit Normalharn controlirt. ${ }^{2}$ ) Auf die Isolirung

1) Congress für innere Medicin. Wiesbaden. April 1905.

2) Der von Embden angegebenen Verbesserung der Methodik haben wir uns bei diesen Versuchen noch nicht bedient. 
sehr geringer Mengen hat sich hierbei unser Interesse nicht gerichtet. Ebenso haben wir bei einer schweren Anämie und auch bei einem Patienten im agonalen Zustand durch Verfütterung sowie durch Injection keine grössere Menge der Aminosäure im Harn antreffen können. Ferner wurden mit gleichem Resultate untersucht zwei Diabetiker, welche noch eine gewisse Toleranz zeigten. Letztere Fälle sind allerdings nur mit inactivem Alanin behandelt. Ein ganz entgegengesetztes Resultat haben wir erhalten bei einem Comatösen, der wenige Tage darauf ad exitum kam. Derselbe erhielt in einmaliger Dosis $15 \mathrm{~g}$ inactives Alanin und wir fanden bei der Verarbeitung des Harns nach der Naphthalinsulfochloridreaction sofort einen stärkeren Niederschlag beim Ansäuern als gewöhnlich. Derselbe fiel zunächst als helles Oel, wurde mit Wasser gewaschen, nochmals umgelöst, worauf er nach längerem Stehen in der Kälte vollständig krystallisirte. Die Substanz wurde einmal aus heissem Wasser umkrystallisirt; sie erschien nummehr rein. Die alkoholische Lösung sowie die Lösung in verdünntem Ammoniak oder verdünnter Natronlauge war stark linksdrehend. Im Capillarröhrchen erhitzt sinterte die Substanz bei $88^{\circ}$ und schmolz bei $115^{\circ}$ (uncorr.). Umlösen und umkrystallisiren aus concentrirter Lösung änderte dies nicht. Im Vacuum getrocknet zunächst bei tiefer Temperatur, dann langsam steigend bei $80^{\circ}$ verlor sie Wasser und zeigte daraufhin einen etwas höheren Schmelzpunkt. Sie sinterte bei $104--105^{\circ}$ und schmolz bei $117-121^{\circ}$. Die Substanz war diesen Ejgenschaften nach anzusprechen als ein Naphthalinsulfoalanin, das wenigstens zum Theil aus der rechtsdrehenden Form, dem D-Alanin bestand, dessen Naphthalinsulfoderivat die Ebene des polarisirten Lichts nach links dreht. Völlig rein war die Substanz nicht. Die Stickstoffanalyse ergab zwar befriedigende Werthe, dagegen genügte die Verbrennung nicht. Es mag daher an dieser Stelle nochmals betont werden, dass wenn man sich zur Abscheidung und Identificirung der Aminosäuren hochmolekularer besonders schwer löslicher Derivate bedient, welche starke Krystallisationskraft zeigen, man der Controle durch die Verbrennung bedarf. Die zunächst erhaltenen Werthe sind: $0,1998 \mathrm{~g}$ gaben 0,4155 Kohlensäure und $0,0877 \mathrm{~g} \mathrm{H}_{2} \mathrm{O}$. Gefunden: Kohlenstoff 56,76 pCt., Wasserstoff 4,87 pCt., berechnet 55,91 pCt. und 4,66 pCt.

Die Substanz wurde nochmals aus sehr verdünntem Aceton umkrystallisirt, aus dem sie sich nach längerem Stehen in harten Krystallen abschied. Die Substanz zeigte noch dieselbe starke Linksdrehung, obgleich natürlich die Gefahr vorlag, bei dem häufigen Umkrystallisiren Verluste an der naturgemäss leichter löslichen optisch activen Verbindung gegenüber dem Racemkörper zu erhalten. Nach gleicher Vorbereitung zur Analyse ergaben sich stimmende Werthe: $0,1693 \mathrm{~g}$ gaben 0,3472 $\mathrm{g}$ Kohlensäure und 0,0730 $\mathrm{g}$ Wasser. Gefunden: Kohlenstoff 55,93 pCt., Wasserstoff 4,79 pCt.

Aus dieser Untersuchung geht zweifellos hervor, dass D-Alanin vorhanden war und wir hatten uns überzeugt, dass diese Verbindung vor der Verfütterung des Racemkörpers nicht anzutreffen war. Es wäre auch höchst unwahrscheinlich gewesen, diese $\Lambda$ minosäure allein, nicht in Bcgleitung anderer Aminosäuren anzutreffen. Auch war die optische 
Activität zu stark, als das es sich etwa um einen Mischungsvorgang beim Krystallisationsprocess hätte handeln können. Wir kommen also doch zu dem Resultat, dass der progresse Diabetiker nach der Einführung von inactivem Alanin D-Alanin ausschied. Es liegt also die Frage vor, ob der complet diabetisch entartete Organismus auch das D-Alanin nicht tolerirt. Es wäre wünschenswerth, dass auf diese Erscheinung geachtet würde, da sie vielleicht für den intermediären Stoffwechsel wichtig ist, falls unser Resultat generell bestätigt werden sollte.

Einen weiteren Versuch wollen wir noch erwähnen, der sich an andere Beobachtungen anschliesst. Der eine von uns hat in Gemeinschaft mit Liepmann beobachtet, dass die Placenta mit Lösungen inactiver Aminosäuren, und zwar auch des Alanins in Berührung gebracht, diese partiell asymmetrisch, verschwinden lässt, indem die gleichfalls als Derivat isolirte Säure einen Gehalt an asymmetrischer Substanz, und zwar des L-Alanin zeigt. Analog haben wir daher die Leber des erwähnten Patienten, dessen Autopsie wenige Tage nachdem der Versuch erfolgte, mit einer Lösung inactiven Alanins digerirt. Hierfür wurde der Leberbrei mit der J,ösung im thermoconstanten Schüttelgefäss ${ }^{1}$ ) bei $40^{0}$ sechs Stunden geschüttelt. Es wurde darauf mit Alkohol gefällt, die alkoholische Lösung verdampft, mit Wasser aufgenommen, entfettet und der Naphthalinsulfochloridreaction unterworfen und mehrfach die erhaltene Substanz umkrystallisirt. Das Resultat war jedoch nur das inactive Derivat, gemischt mit einer geringen Menge der L-Alaninverbindung. Der Versuch hat natürlich nur geringe Bedeutung. Die Methode, diese Vorgänge durch genaue Verfolgung ihrer Asymmetrie zu erforschen, dürfte dagcgen zuweilen auch fernerhin vortheilhaft anwendbar sein.

1) Schüttelflaschen nach Art der Dewargefässe construirt und für die Schüttelmaschine passend, benutzen wir für vielfache thermoconstante Operationen, wie Verdaungsversuche, Extractionen bei bestimmter Temperatur (z. B. Eiswasser) und für Löslichkeitsbestimmungen. Nach eigenen Angaben hergestellt von Gebr. Muencke, Berlin, Schumannstr. 